\title{
An experimental study of radiative fluxes in the south Bay of Bengal during BOBMEX 1999
}

\author{
K Gopala Reddy, G Bharathi, A Ravi Kumar, M V Subrahmanyam and \\ K MUNi KRISHNA \\ Department of Meteorology and Oceanography, Andhra University, Visakhapatnam 530 003, India.
}

Time series measurements of radiative fluxes were made onboard INS Sagardhwani (SD) in the south Bay of Bengal near DS3 $\left(13^{\circ} \mathrm{N}\right.$ and $\left.87^{\circ} \mathrm{E}\right)$ during the BOBMEX field experiment. An intercomparison experiment conducted at DS3 showed that the radiative fluxes measured by Kipp and Zonen, Albedo meter and net Pyrgeometer onboard SD and by Eppley radiometers onboard ORV Sagar Kanya (SK) are well matched. It may be mentioned that the measurements showed consistency and good agreement between SD and SK ships, even though no Gimbal mounting was used for radiation instruments onboard SD.

The main aim of the experiment was collection of high quality radiation data during the monsoon period, which can give an insight into the nature of the ocean-atmosphere coupling. The data on the four radiative fluxes collected on SD are averaged at 5 minute intervals and then hourly and daily averages have been computed. The hourly shortwave albedo and the atmospheric transmission factor are also computed and the variation of albedo in relation to the solar altitude and the transmissivity factor (TF) are studied. The mean albedo over the south Bay of Bengal under clear, partly cloudy and overcast skies are found to be $0.05,0.07$ and 0.2 respectively.

\section{Introduction}

An experiment called Bay of Bengal Monsoon Experiment (BOBMEX-99) was designed near DS3 $\left(13^{\circ} \mathrm{N}, 87^{\circ} \mathrm{E}\right)$ onboard INS Sagardhwani (SD) and near DS4 $\left(18^{\circ} \mathrm{N}, 8^{\circ} \mathrm{E}\right)$ onboard ORV Sagar Kanya (SK) in south and north Bay respectively, to study the various processes in the Bay of Bengal which are responsible for the ocean-atmosphere coupling, the variability of the Indian monsoon and other convective systems, under the Indian Climate Research Programme (ICRP). Earlier field programs such as MONSOON-77, MONEX-79 and MONTBLEX-90 had made extensive measurements in the Indian Ocean but not to the level of the BOBMEX-99 investigation in the Bay of Bengal. Past experiments over the Bay had certain limitations. The surface fluxes were derived using bulk aerodynamic formulae and longwave flux was not directly measured and have been estimated from empirical formulae that have large uncertainties.

Some results from the BOBMEX-99 observations of the atmosphere and ocean were published by Bhat et al 2001. The occurrence of organized convection is high in south and north Bay locations. During the northward propagation of the tropical convergence zone the systems tend to move across the Bay from south to north (Sikka and Gadgil 1980). The variation of the OLR derived from INSAT for the grid boxes in the north and south Bay and SST and wind speed measured from the buoys in BOBMEX-99 period show several active spells with low OLR occurring at intervals varying between 5 and 9 days. The duration of each of these spells varies from 2-5 days. Between these active spells there are spells with almost cloud free conditions, i.e., with high OLR, which last for 2-3 days (Bhat et al 2001). The radiative flux data collected onboard

Keywords. Bay of Bengal; radiative fluxes; BOBMEX-99. 
Table 1. Radiation instruments operated during BOBMEX-99.

\begin{tabular}{|c|c|c|c|c|c|c|c|}
\hline Parameter & Platform & Instrument & Location & Make & Accuracy & $\begin{array}{l}\text { Averaging } \\
\text { time }\end{array}$ & Sampling interval \\
\hline \multirow{3}{*}{$\begin{array}{l}\text { Shortwave } \\
\text { radiation } \\
\text { (incoming } \\
\text { and outgoing) }\end{array}$} & SD & Albedometer & Boom & $\begin{array}{l}\text { Kipp and } \\
\text { Zonen, } \\
\text { Netherlands }\end{array}$ & $\sim 10 \mathrm{~W} / \mathrm{m}^{2}$ & $5 \min$ & Continuous \\
\hline & SK & $\begin{array}{l}\text { Spectral } \\
\text { Pyranometers }\end{array}$ & $\begin{array}{l}\text { Gimbal } \\
\text { (incoming) }\end{array}$ & Eppley, USA & $\sim 10 \mathrm{~W} / \mathrm{m}^{2}$ & $1 \mathrm{~min}$ & \\
\hline & & & $\begin{array}{l}\text { Boom } \\
\text { (outgoing) }\end{array}$ & & & $1 \mathrm{~min}$ & Continuous, $1 \mathrm{~Hz}$ \\
\hline \multirow{3}{*}{$\begin{array}{l}\text { Longwave } \\
\text { radiation } \\
\text { (incoming } \\
\text { and outgoing) }\end{array}$} & $\mathrm{SD}$ & $\begin{array}{l}\text { Net } \\
\text { Pyrgeometer }\end{array}$ & Boom & $\begin{array}{l}\text { Kipp and } \\
\text { Zonen }\end{array}$ & $\pm 10 \%$ & $5 \min$ & Continuous \\
\hline & SK & & $\begin{array}{l}\text { Gimbal } \\
\text { (incoming) }\end{array}$ & Eppley & & $1 \mathrm{~min}$ & Continuous, $1 \mathrm{~Hz}$ \\
\hline & & $\begin{array}{l}\text { IR } \\
\text { radiometers }\end{array}$ & $\begin{array}{l}\text { Boom } \\
\text { (outgoing) }\end{array}$ & & $\sim 10 \mathrm{~W} / \mathrm{m}^{2}$ & $1 \mathrm{~min}$ & Continuous, $1 \mathrm{~Hz}$ \\
\hline
\end{tabular}

SK is being scrutinized by the IISc investigators.

In spite of the importance of the radiative fluxes, observations of all the four radiative fluxes over the Bay of Bengal have not been directly measured over the Bay previously. Therefore, as a part of the Bay of Bengal Monsoon Experiment (BOBMEX99), Andhra University (AU) with DST support has participated in the radiative flux observational program on the DRDO ship INS Sagardhwani (SD) in the south Bay of Bengal near DS3. Observations were made in four phases during 16th July29th August 1999 with breaks during 23rd -27th July, 2nd-9th and 17th-22nd August for port calls by SD.

The radiative flux data collected onboard SD is presented in this manuscript. The hourly and daily variations of the radiative fluxes over the south Bay of Bengal and the variation of the shortwave albedo and its relation to the solar altitude and the atmospheric transmission are examined. We briefly discuss the instrumentation, experimental setup, calibration and inter-comparison of the radiation instruments in the next section. In section 3 , data and method of analysis are presented. Results from the observations and its variability with other surface meteorological parameters are presented in section 4 and summary in section 5 .

\section{Instrumentation}

During BOBMEX-99, the four components of radiation namely, incoming shortwave radiation, incoming longwave radiation, reflected shortwave radiation, and outgoing longwave radiation, were measured on both the ships (SD and SK). IISc had installed Eppley radiation instruments on SK while
Andhra University had installed Kipp and Zonen radiation instruments on SD. The details of these instruments are given in table 1.

\subsection{Experimental setup}

The experimental arrangement onboard SD consisted of the Albedometer and net Pyrgeometer fixed on a boom extending out about $5 \mathrm{~m}$ horizontally in front of the bow. The two sensors of the Albedometer share a common body and is mounted on a steel rod with a diameter of $16 \mathrm{~mm}$ and length $500 \mathrm{~mm}$. Similarly, the two sensors of the net Pyrgeometer also share a common body with a similar mounting rod as above. The Albedometer and the net Pyrgeometer are fixed on either side of an iron plate on the boom. In the present study Gimbal mounting was not possible, as both the Albedometer and net Pyrgeometer share a common body for the upward and downward looking sensors. The sensors of the radiometers are connected to the data logger CR10X placed on the deck. The data logger is connected to a personal computer located in the meteorological lab in the ship.

\subsection{Calibration}

The Albedo meter and net Pyrgeometer were calibrated at IMD and compared with the standards at the Central Radiation Laboratory, Indian Meteorological Department, Pune. The calibration factors are almost similar to those given by the manufacturer. Also, the performance and accuracy of the radiometer sensors of Kipp and Zonen have been compared with those of Eppley at CAOS, Indian Institute of Science, Bangalore and the results show consistency and good agreement between the two. 
The calibration factors as given by the manufacturer have been used in the present observational program. Sensors were cleaned regularly to protect from sea spray, dust and soot.

\subsection{Inter-comparison experiment of the radiation instruments}

Inter comparison experiment (ICE2) was carried out near DS3 location on 27th August 1999 during the day time for $12 \mathrm{~h}$ duration, to assess the relative accuracy of the data observed from different radiation instruments measuring the same variable on two ships (SD and SK). Considering the instrument alignment and output voltage measurement errors, the accuracy of the radiation instruments is in the $10-20 \mathrm{~W} / \mathrm{m}^{2}$ range. Thus the differences between SK and SD radiation data are well within the overall instrument errors. This indicates that BOBMEX-99 radiation data can be used without any corrections. (Bhat et al, ICRP 2000). The different components of radiation measured are shown in figure 4 and the results are presented in section 4.2 .

It may be noted that though Gimbal mounting was not used in the case of Kipp and Zonen instruments, the radiative fluxes are in good agreement with those of Eppley, which were mounted on a Gimbal. This could be because, the minor errors in the fluxes due to platform rolling and pitching might be minimized because of the continuous measurement and averaging at 5 minute intervals. Also, as the measurements are made at lower latitudes $\left(13^{\circ} \mathrm{N}, 87^{\circ} \mathrm{E}\right)$, the errors due to platform motion are not too serious, as suggested by Katsaros and DeVault (1986) and MacWhorter and Weller (1991).

\section{Data and method of analysis}

The shortwave fluxes are measured by the Albedometer, CM 7B of Kipp \& Zonen B.V., Netherlands, which is based on two CM 6B Pyranometer sensors. Similarly, the net Pyrgeometer CG2 of the same company, which is based on two CG1 sensors, is used to measure the longwave fluxes.

The irradiance $\left(\mathrm{W} / \mathrm{m}^{2}\right)$ value can be computed by multiplying the output signal $(V)$ of the Pyranometer with the reciprocal of the sensitivity figure (calibration factor, $K$ ).

$$
\text { Irradiance }\left(\mathrm{W} / \mathrm{m}^{2}\right)=V * 1 / K \text {. }
$$

The Pyrgeometer is designed for measurement of far infrared radiant flux (5 to $25 \mu \mathrm{m}$ ). The longwave fluxes can be calculated by measuring the output voltage $V$, the detector temperature $T s$ and taking the calibration factor $K$ into account,

$$
L=V / K+5.67 * 10-8 * T_{s}^{4} .
$$

The calibration factor, $K$ is given by

$$
K=\frac{V_{20{ }^{\circ} \mathrm{C}}-V_{30^{\circ} \mathrm{C}}}{5.67 * 10^{8}(60.6)},
$$

where $V_{20}{ }^{\circ} \mathrm{C}$ and $V_{30}{ }^{\circ} \mathrm{C}$ are the output voltage at $20^{\circ} \mathrm{C}$ and $30^{\circ} \mathrm{C}$.

Continuous data on the four components of radiation are collected in milli volts and recorded in the data logger, which are then transferred to a personal computer and stored. The collected data are converted into the radiative fluxes by using the corresponding calibration factors of the sensors and averaged at 5-minute intervals for further analysis.

During the phase I and II, there are data gaps for shortwave and longwave radiation as shown in figure 1. During phase I the data were collected for only three days (17th, 18th and 19th July, 1999). On the subsequent 3 days during this phase the data could not be collected. These are due to the technical problems in the data logger and due to some software problem in transferring the data from data logger to computer, which could not be rectified onboard the vessel. This was rectified later when the ship came back to Chennai after the end of phase II. During phases III and IV, all the four radiative fluxes were collected.

The incoming shortwave flux data gaps as given in figure 1 were filled for hourly/daily estimates by using Lumb (1964) formulae and the observed cloud amount and type. The hourly values are estimated by using these formulae based on cloud amount and type. The distance correction is also included as given below:

$$
Q_{T}=(\bar{d} / d)^{2} \times S_{0} \times \sin h,
$$

where

$$
\begin{aligned}
Q_{T}= & \text { incoming shortwave radiation at the } \\
& \text { top of atmosphere, } \\
(\bar{d} / d)^{2}= & \text { distance correction for revolution of } \\
& \text { the earth, } \\
S_{0}= & \text { solar constant }\left(\mathrm{W} \mathrm{m}^{-2}\right), \text { and } \\
\sin h= & \text { sine of the solar altitude which is cal- } \\
& \text { culated from the date, time and loca- } \\
& \text { tion }
\end{aligned}
$$

and

$$
Q_{S W \downarrow}=Q_{T} *\left(A_{i}+B_{i} * \sin h\right),
$$

where $Q_{S W \downarrow}=$ incoming shortwave radiation at the surface.

$A_{i}$ and $B_{i}$ are regression coefficients for nine categories based on cloud amount and type. 


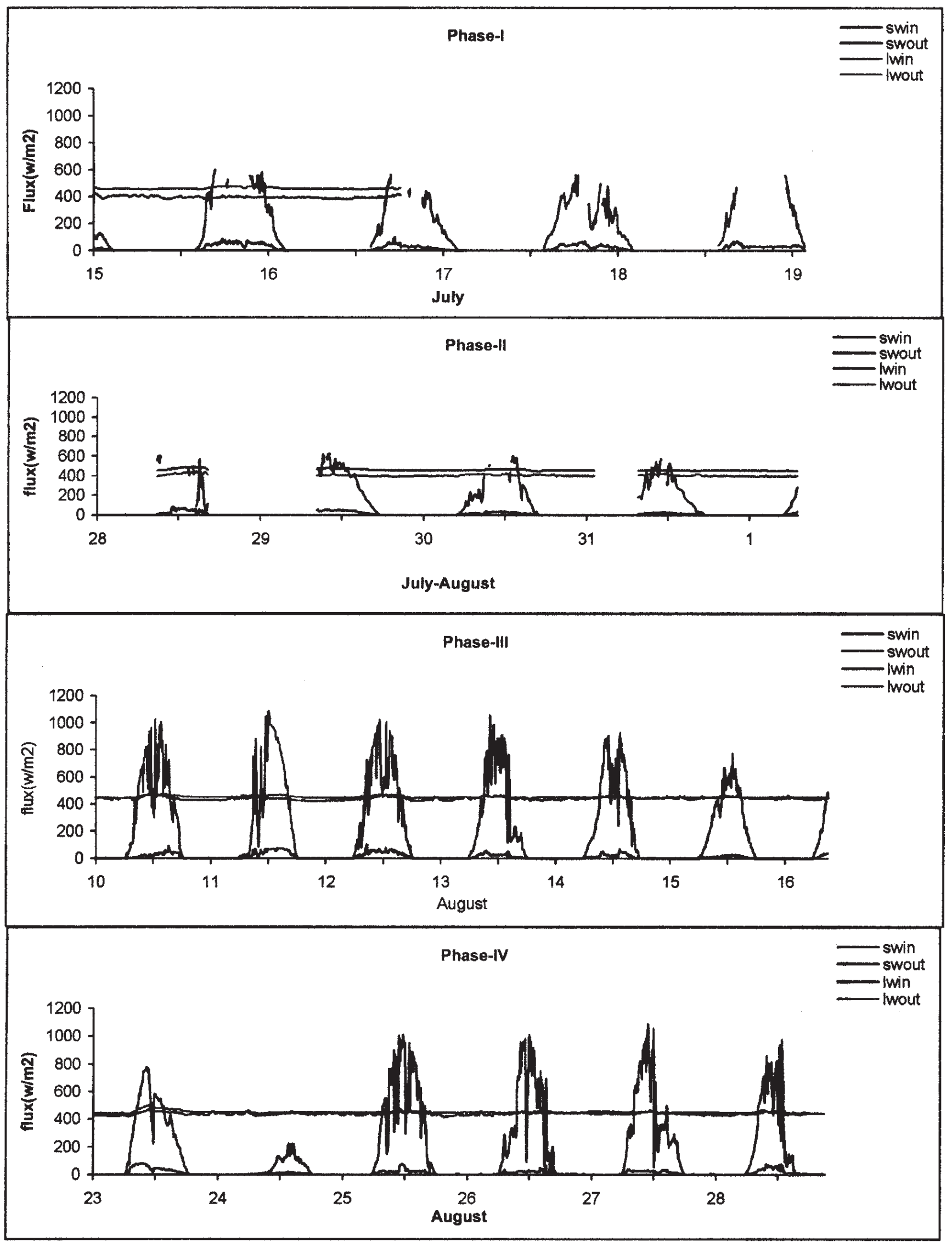

Figure 1. Time series of shortwave and longwave radiation during the period of observation. 
During phase I, hourly incoming longwave flux is not recorded for few days (17th-19th July). For these days, longwave flux is estimated by using Anderson (1952) formula (Fung et al 1984) and surface meteorological observations data. The net longwave radiation in the presence of cloud is estimated by incorporating a linear cloud factor dependent on cloud type to the corresponding Anderson's clear sky estimates (Gopala Reddy and Fechner 1987).

$$
L W_{\downarrow}=\varepsilon \sigma T_{a}^{4}(0.74+0.0049 * e a) * F c,
$$

where

$\varepsilon=$ emissivity of the surface,

$\sigma=$ Stefan-Boltzman constant,

$T_{a}=$ air temperature,

$e a=$ vapour pressure of air.

$$
F c=\left(1-\sum_{i=0}^{n} k_{i} C_{i}\right) .
$$

The cloud factor $(F c)$ is calculated by weighting values for individual cloud types $\left(k_{i}\right)$ by the fraction cloud amount of that time $C_{i}$ as given by Sellers (1965)

From the measured shortwave radiative fluxes, the albedo and the atmospheric transmission factor are computed as follows:

$$
\begin{aligned}
\text { Shortwave albedo } & =\frac{Q_{S W \uparrow}}{Q_{S W \downarrow}}, \\
\text { Transmission factor (T.F.) } & =\frac{Q_{S W \downarrow}}{Q_{T}},
\end{aligned}
$$

where

$$
\begin{aligned}
Q_{S W \downarrow}= & \text { incoming shortwave radiation at the } \\
& \text { surface, } \\
Q_{S W \uparrow}= & \text { reflected shortwave radiation at the } \\
& \text { surface, and } \\
Q_{T}= & \text { incoming shortwave radiation at the } \\
& \text { top of atmosphere. }
\end{aligned}
$$

\section{Results and discussion}

\subsection{Time series observations}

The time series of the four radiative fluxes averaged at 5-minute intervals during the period of study are presented in figure 1. As mentioned above, there are some gaps in the data during phase I and II. The incoming shortwave radiation is maximum $\left(1091 \mathrm{~W} / \mathrm{m}^{2}\right)$ on 11 th August at $10: 55 \mathrm{hrs}$ and another maximum $\left(1090 \mathrm{~W} / \mathrm{m}^{2}\right)$ is noticed on 27th August at 12:00 hrs. The outgoing shortwave radiation is maximum $\left(102.6 \mathrm{~W} / \mathrm{m}^{2}\right)$ on 19 th July at 9:20 hrs and another maximum $\left(99.9 \mathrm{~W} / \mathrm{m}^{2}\right)$ is noticed on 12th August at 8:30 hrs. The incoming longwave radiation is maximum $\left(486 \mathrm{~W} / \mathrm{m}^{2}\right)$ on 10th August at 11:35 hrs and a secondary maximum $\left(477.7 \mathrm{~W} / \mathrm{m}^{2}\right)$ is noticed on $23 \mathrm{rd}$ August at 11:30 hrs. The outgoing longwave radiation is maximum $\left(500 \mathrm{~W} / \mathrm{m}^{2}\right)$ on 23rd August at 10:45 hrs and a secondary maximum $\left(488.5 \mathrm{~W} / \mathrm{m}^{2}\right)$ is noticed on 28 th July at 14:50 hrs. Longwave radiation shows little variation, and the range of incoming longwave radiation is $382-486 \mathrm{~W} / \mathrm{m}^{2}$ and outgoing longwave radiation is $422-500 \mathrm{~W} / \mathrm{m}^{2}$.

\subsection{Inter-comparison experiment result}

As shown in figure 4, longwave radiation shows little variation with time, and differences between longwave radiation data (incoming and outgoing) from both the ships have been plotted together without labeling data from different instruments. There were cumulus clouds in the sky and their shadows caused short-term fluctuations in the solar radiation. It is seen that there is an excellent agreement between the incoming solar radiation measured on both ships. The values differ only in the presence of clouds presumably due to the fluctuations, which differ at the two locations. The decrease in shortwave radiation around noon time shows that cumulonimbus $(\mathrm{Cb})$ cloud arrived at SK several minutes before that at SD and is consistent with the rain gauge data showing early arrival of rain at SK.

The average values of incoming solar radiation for the inter-comparison period (6 a.m. to 6 p.m.) are $408 \mathrm{~W} / \mathrm{m}^{2}$ and $409 \mathrm{~W} / \mathrm{m}^{2}$ on SK and SD respectively. The reflected solar radiation is much smaller and the average values are $13 \mathrm{~W} / \mathrm{m}^{2}$ and $20 \mathrm{~W} / \mathrm{m}^{2}$ on SK and SD respectively. (One possible reason for the relatively large difference in the reflected radiation could be that the signal levels are small and comparable to the instrument accuracies.) These values imply an albedo of 3 to $5 \%$, which is in close agreement with that of $6 \%$ suggested by Payne (1972) based on measurements made at $41^{\circ} \mathrm{N}$ over the sea near the east coast of USA. Longwave radiation did not show diurnal trend. The average incoming longwave radiation measured on SK is $435 \mathrm{~W} / \mathrm{m}^{2}$ and the corresponding value on $\mathrm{SD}$ is $447 \mathrm{~W} / \mathrm{m}^{2}$. The average outgoing radiation measured on SK is $456 \mathrm{~W} / \mathrm{m}^{2}$ and that on the SD is $450 \mathrm{~W} / \mathrm{m}^{2}$ (Bhat et al, ICRP 2000).

\subsection{Mean hourly variation of the radiative fluxes}

\subsubsection{Shortwave $(S W)$ fluxes}

From the 5-minute averages, the hourly average fluxes have been computed and presented in 


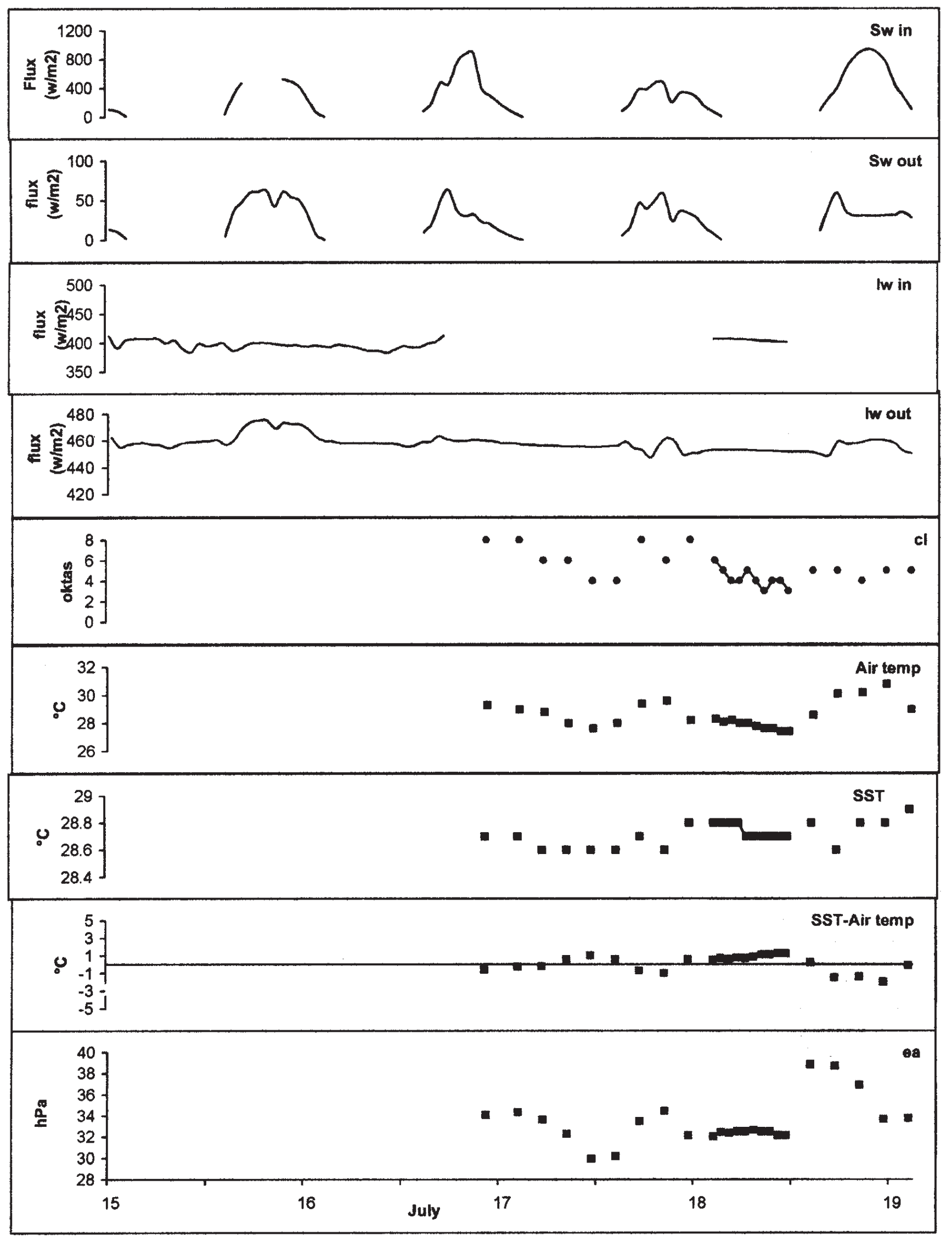

Figure 2(a). Hourly variation of radiation fluxes and surface meteorological parameters during phase I. 


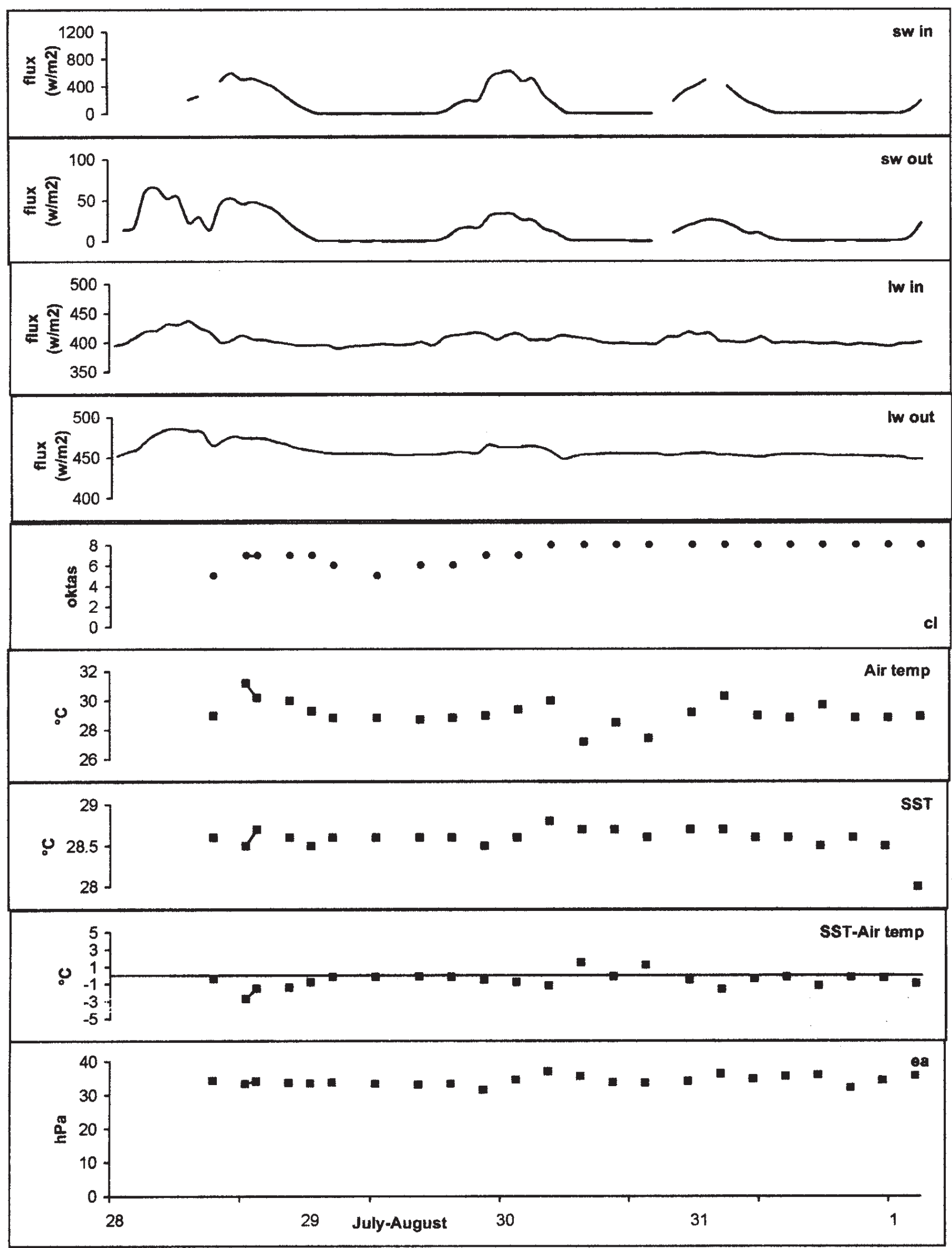

Figure 2(b). Hourly variation of radiation fluxes and surface meteorological parameters during phase II. 


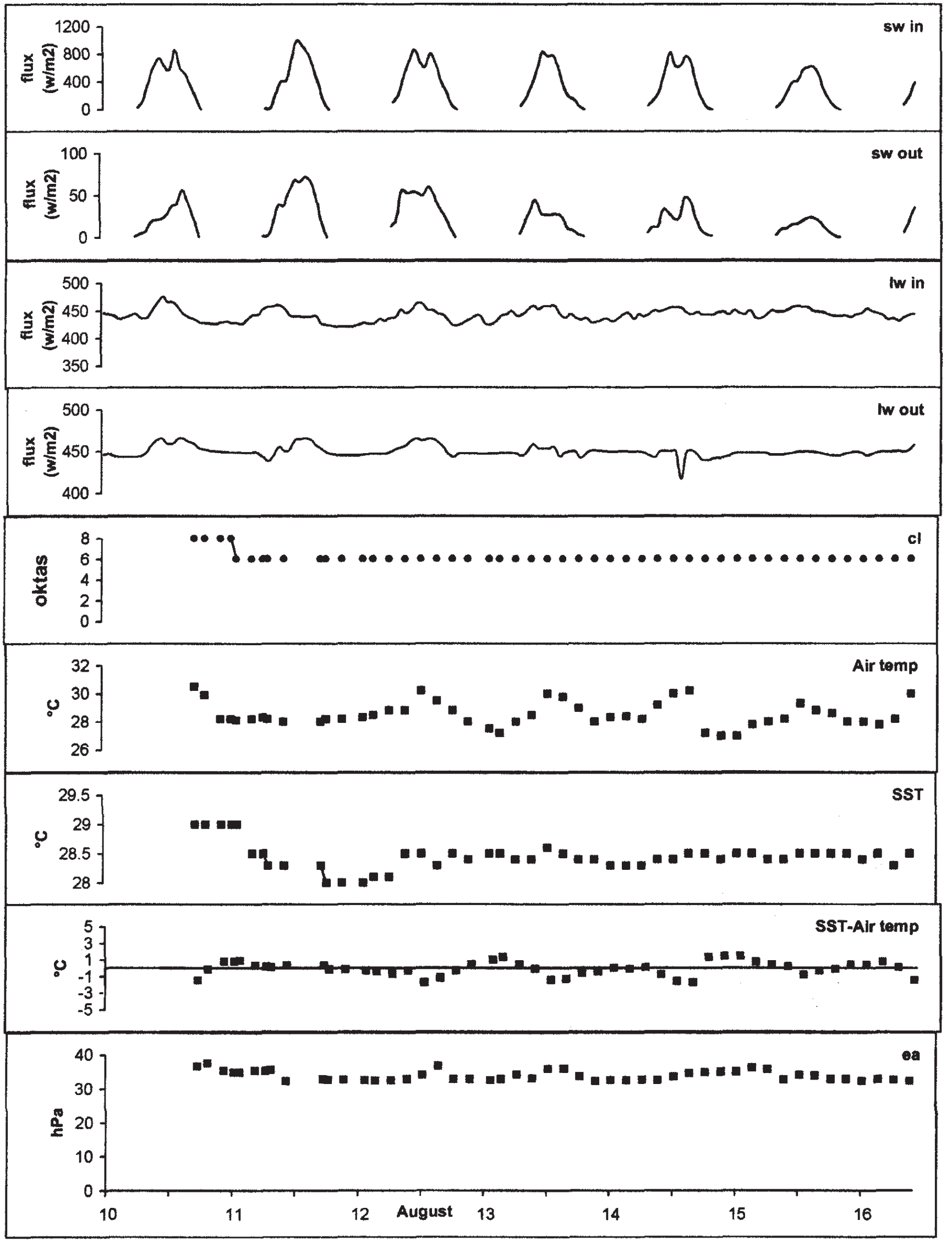

Figure 2(c). Hourly variation of radiation fluxes and surface meteorological parameters during phase III. 


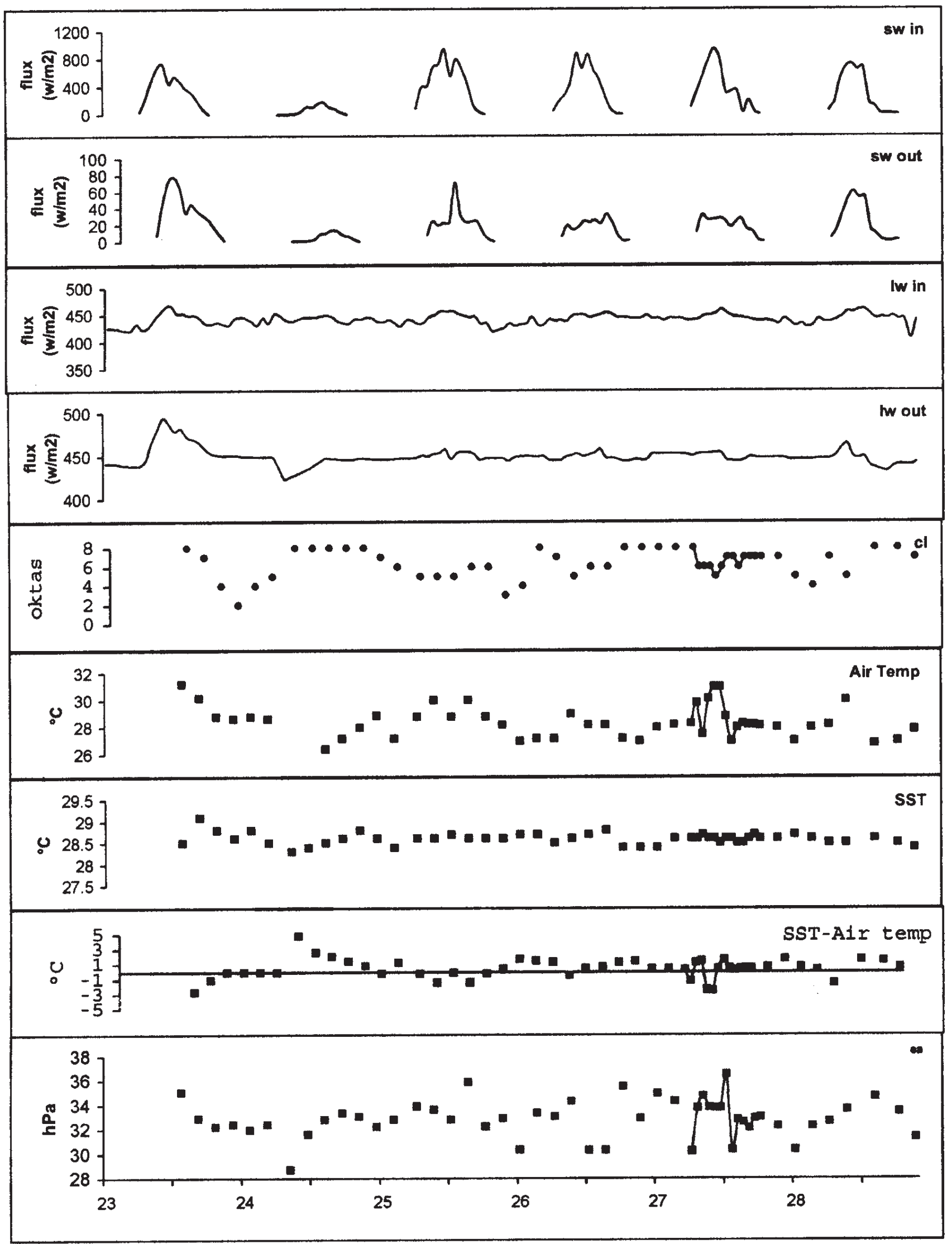

Figure 2(d). Hourly variation of radiation fluxes and surface meteorological parameters during phase IV. 


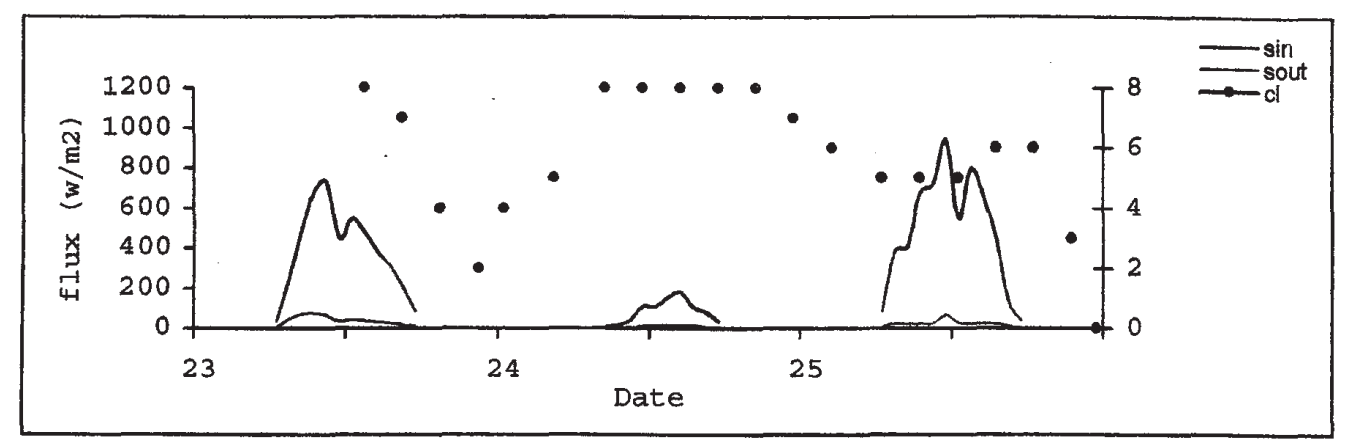

Figure 3. Hourly variation of shortwave radiation during 23rd - 25th August.

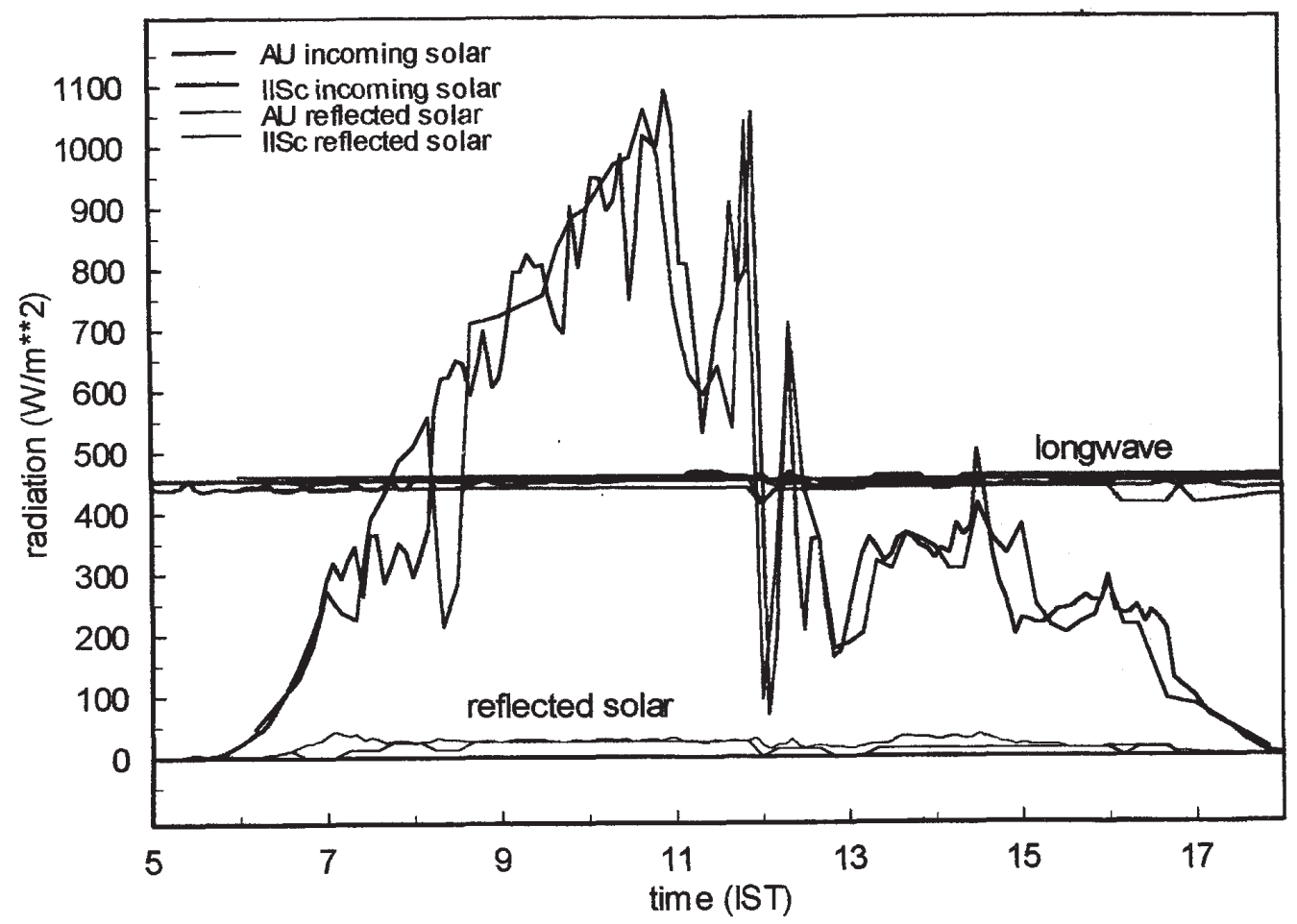

Figure 4. Comparison of IISc and Andhra University radiation data collected during ICE2. Since values of longwave radiation are nearly constant and close to each other, data from individual instruments are not shown.

figures $2(\mathrm{a})-(\mathrm{d})$ for all the phases. While calculating the averages, the data gaps of a few hours are filled with the estimated values using equation (5) and cloud observations (amount and type) for different synoptic hours. The range of hourly variation during $0600-1800 \mathrm{hrs}$ of the shortwave fluxes during different phases are given below:

\begin{tabular}{lcc}
\hline & $\mathrm{SW}_{\downarrow}\left(\mathrm{W} / \mathrm{m}^{2}\right)$ & $\mathrm{SW}_{\uparrow}\left(\mathrm{W} / \mathrm{m}^{2}\right)$ \\
\hline Phase I & $4-899$ & $1-52$ \\
Phase II & $3-673$ & $1-33$ \\
Phase III & $3-767$ & $1-44$ \\
Phase IV & $2-673$ & $1-36$ \\
\hline
\end{tabular}

\subsubsection{Shortwave fluxes during disturbed weather conditions}

A low pressure area was generated over south central Bay on 24th August and crossed land on 27th August. Under this influence markedly low values of shortwave fluxes occurred. Figure 3 shows the hourly average of shortwave fluxes along with 3-hr cloud amount for three days 23rd-25th August. On 23rd August incoming shortwave radiation is maximum $\left(731 \mathrm{~W} / \mathrm{m}^{2}\right)$ at $1000 \mathrm{hrs}$ and decreased from noon time with increase of cloud amount to 8 oktas and type Sc and As. The cloud amount decreased during night time to 2 oktas. On 24th August the cloud amount was 8 oktas (St/As) dur- 
Table 2. Variation of albedo in relation to sine of the solar altitude.

\begin{tabular}{lcccccccccc}
\hline & \multicolumn{8}{c}{ Sine of the solar altitude } & \\
\cline { 2 - 9 } & 0.1 & 0.2 & 0.3 & 0.4 & 0.5 & 0.6 & 0.7 & 0.8 & 0.9 & Total \\
\hline No. of samples & 87 & 137 & 133 & 135 & 148 & 159 & 173 & 186 & 241 & 1691 \\
SW in & 28.7 & 57.6 & 104.7 & 169.3 & 223.2 & 303.5 & 358.2 & 472.6 & 585.2 & 359.8 \\
SW out & 3.7 & 6.4 & 11.2 & 16.3 & 19.1 & 24.4 & 26.0 & 29.2 & 31.7 & 22.8 \\
Albedo & 0.18 & 0.11 & 0.10 & 0.10 & 0.09 & 0.08 & 0.07 & 0.06 & 0.06 & 0.08 \\
\hline
\end{tabular}

Table 3. Variation of albedo in relation to the transmission factor (T.F.).

\begin{tabular}{llccc}
\hline T.F. & \multicolumn{1}{c}{ Cloud } & $\mathrm{N}$ & Mean T.F. & Mean albedo \\
\hline (Mean + SD) classification & & & & \\
\hline$<0.2$ & Overcast & 369 & 0.11 & 0.13 \\
$0.2 \leq$ T.F. $\leq 0.6$ & Partly cloudy & 1299 & 0.37 & 0.08 \\
$>0.6$ & Clear sky & 424 & 0.69 & 0.05 \\
\hline Payne classification & & & & \\
\hline$<0.1$ & & 133 & 0.05 & 0.20 \\
$0.1 \leq$ T.F. $\leq 0.65$ & Overcast & 0.36 & 0.07 \\
$>0.65$ & Partly cloudy & 1675 & 0.72 & 0.05 \\
\hline
\end{tabular}

ing day time and a drizzle was reported at $0730 \mathrm{hrs}$ with Cb. On 24th August under the influence of low pressure system the incoming shortwave radiation drastically reduced and the peak value of incoming shortwave radiation is only $180 \mathrm{~W} / \mathrm{m}^{2}$ at $1400 \mathrm{hrs}$. On 25th August the low pressure system moved northwards resulting in decreasing cloud amount of 4-6 oktas, and an increase in incoming shortwave radiation to $942 \mathrm{~W} / \mathrm{m}^{2}$ at $1100 \mathrm{hrs}$ as shown in figure 3. The outgoing shortwave radiation is only $14 \mathrm{~W} / \mathrm{m}^{2}$ on 24 th August while the values are $78 \mathrm{~W} / \mathrm{m}^{2}$ on $23 \mathrm{rd}$ August and $70 \mathrm{~W} / \mathrm{m}^{2}$ on $25 \mathrm{th}$ August.

\subsubsection{Albedo and its variations}

The values of shortwave albedo as calculated from equation (7) in the south Bay are classified into 9 groups based on the corresponding values of $\sin h$ from 0.1 to 0.9 and presented in table 2 to study the variation of albedo in relation to the sine of the solar altitude. From table 2, it can be seen that the albedo is in general high at low solar altitudes and low at high solar altitudes. There is an inverse relationship between albedo and $\sin h$ over the south Bay of Bengal.

The atmospheric transmission factor, which gives an idea about the state of the sky, is calculated by using equation (8) from the measured shortwave incoming radiation $\left(\mathrm{SW}_{\downarrow}\right)$ at 5 -minute intervals and the incoming solar radiation at the top of the atmosphere calculated from equation (4).
The mean and standard deviation (sd) of TF during the period of study are found to be 0.39 and 0.2 respectively. On the basis of the mean and sd, all the values of TF are classified into three groups that may represent the state of the sky as clear $(\mathrm{TF}>$ mean $+\mathrm{sd})$, partly cloudy (mean - sd $<$ $\mathrm{TF}<$ mean $+\mathrm{sd})$ and overcast $(\mathrm{TF}<$ mean $-\mathrm{sd})$. A similar classification has been made by Payne (1972) also. The mean albedo in these three groups has been calculated and presented in table 3. As shown in the table, the mean albedo over the south Bay of Bengal varied from a minimum of 0.05 (clear sky) to 0.13 (overcast sky). Similarly, as per the Payne classification, the albedo varied from 0.05 (clear sky) to 0.20 (overcast sky).

\subsubsection{Longwave (LW) fluxes}

From the 5-minute averages, the hourly average fluxes have been computed. During phase I, the data gaps in incoming longwave radiation are filled by using equation (6) and surface meteorological parameters. The range of hourly variation of the longwave fluxes during different phases are given below:

\begin{tabular}{lcc}
\hline & $\mathrm{LW}_{\downarrow}\left(\mathrm{W} / \mathrm{m}^{2}\right)$ & $\mathrm{LW}_{\uparrow}\left(\mathrm{W} / \mathrm{m}^{2}\right)$ \\
\hline Phase I & $390-415$ & $455-463$ \\
Phase II & $394-419$ & $452-469$ \\
Phase III & $426-459$ & $446-457$ \\
Phase IV & $431-457$ & $445-457$ \\
\hline
\end{tabular}




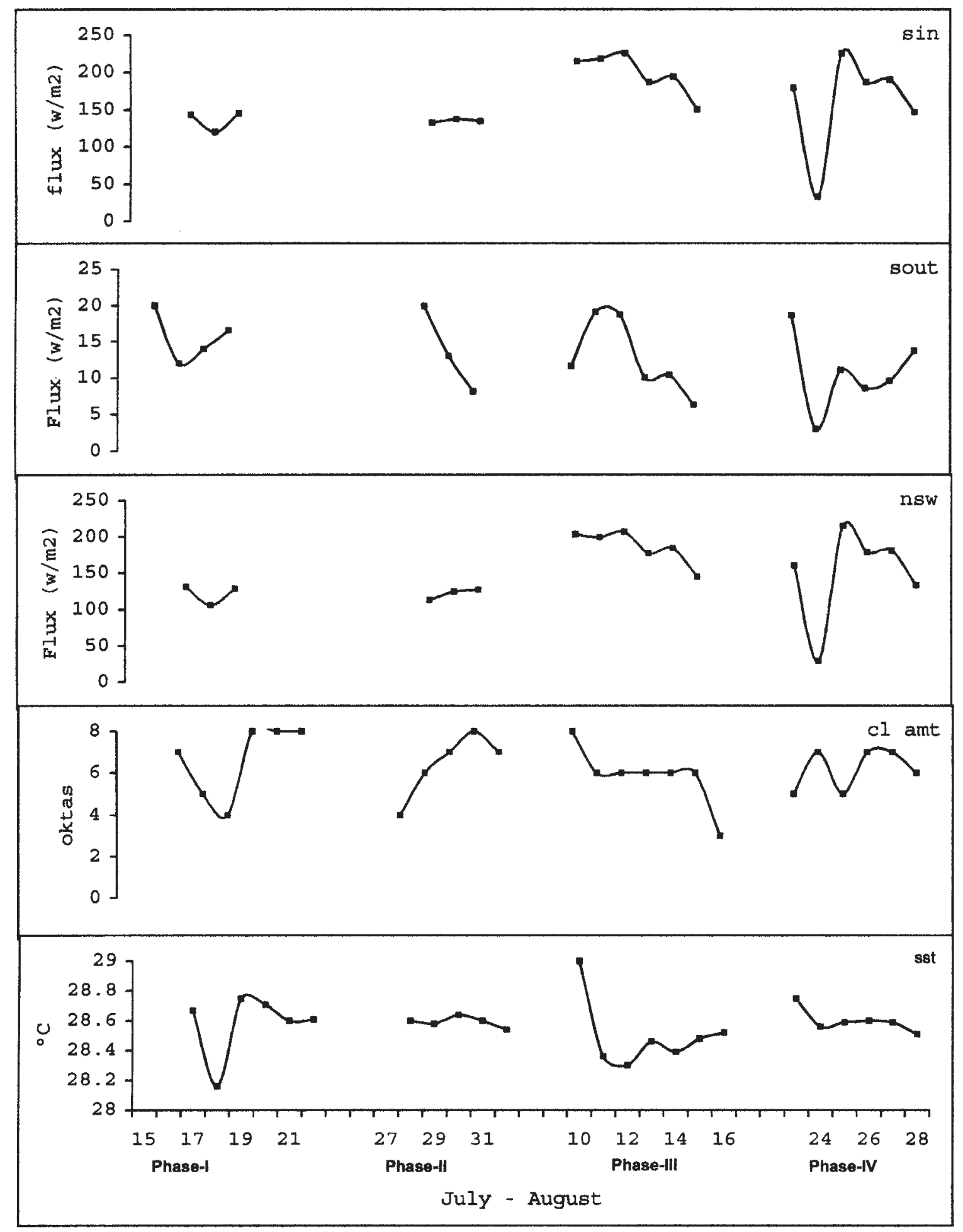

Figure 5. Daily variation of shortwave radiation with cloud amount and SST.

\subsection{Mean daily variation of the radiative fluxes}

The mean daily variation of the radiative fluxes are obtained from the hourly values.

\subsubsection{Shortwave $(S W)$ fluxes}

Variations of the daily shortwave radiative fluxes for the period of study are presented in figure 5. The incoming SW flux varied from $33 \mathrm{~W} / \mathrm{m}^{2}$ 


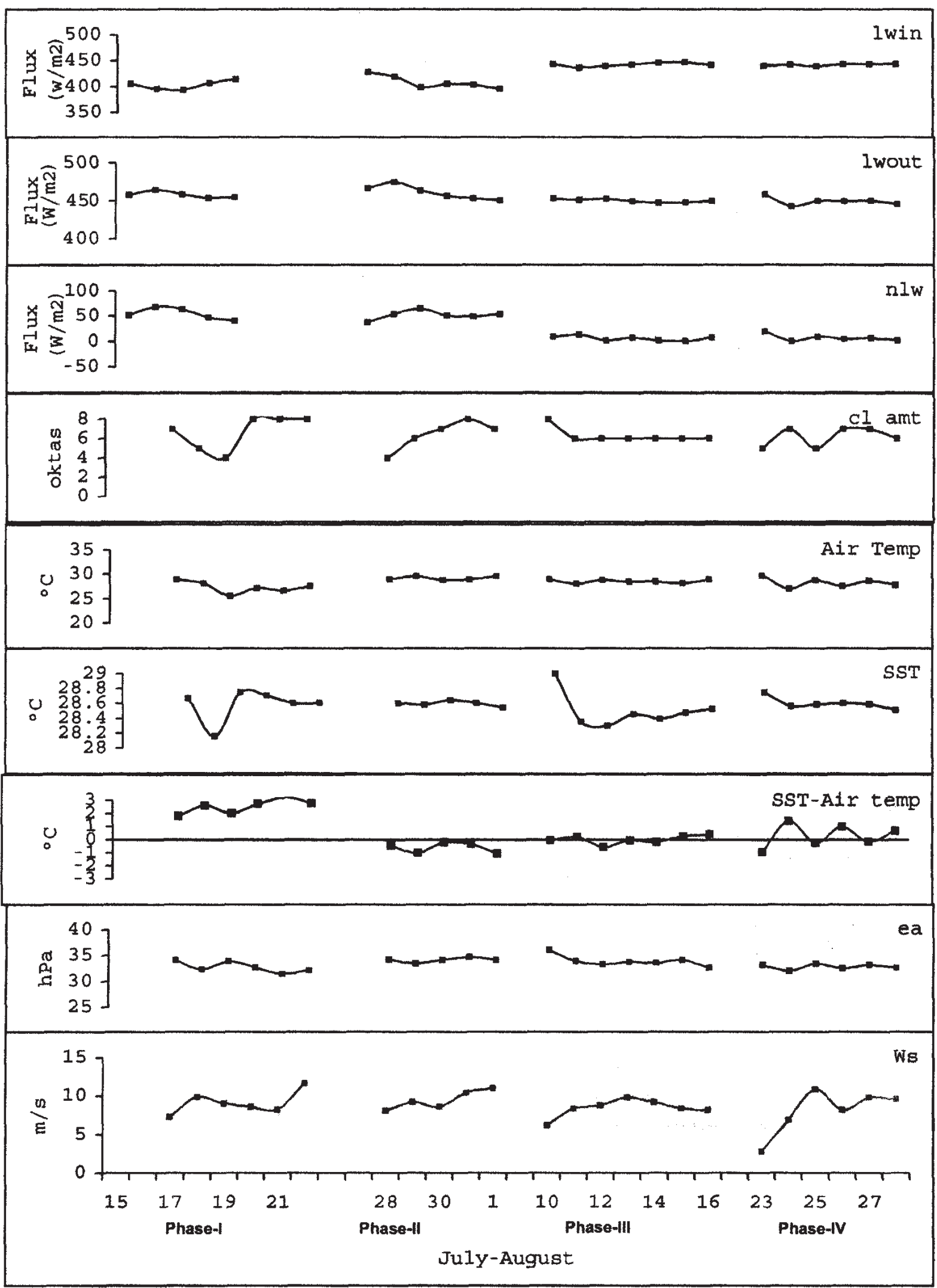

Figure 6. Daily variation of longwave radiation and surface meteorological parameters. 


\begin{tabular}{|c|c|c|c|c|c|c|c|}
\hline & $\operatorname{SST}\left({ }^{\circ} \mathrm{C}\right)$ & $\operatorname{AT}\left({ }^{\circ} \mathrm{C}\right)$ & SST-AT $\left({ }^{\circ} \mathrm{C}\right)$ & Wind $(\mathrm{m} / \mathrm{s})$ & Pressure (hpa) & $\begin{array}{c}\text { Cloud } \\
\text { amount } \\
\text { (oktas) }\end{array}$ & ea (hpa) \\
\hline Phase I & $28.16-28.75$ & $25.56-29.03$ & $1.8-3.24$ & $7.3-11.66$ & 1004.5-1006.3 & $4-8$ & $31.52-33.85$ \\
\hline Phase II & $28.54-28.64$ & $28.84-29.59$ & $-1.03--0.2$ & $8.1-10.43$ & $1005.9-1006.5$ & $4-8$ & $33.49-34.71$ \\
\hline Phase III & 28.3-29 & $28.15-29.03$ & $-0.56-0.4$ & $6.2-9.2$ & $1008.2-1009.4$ & $5-8$ & $32.63-36.12$ \\
\hline Phase IV & $28.51-28.75$ & $27.14-28.83$ & $-0.24-1.42$ & $2.8-10.9$ & $1006.7-1009.2$ & $5-7$ & $32.03-33.46$ \\
\hline
\end{tabular}

(24th August) to $226 \mathrm{~W} / \mathrm{m}^{2}$ (25th August). The reflected SW flux varied little from $3 \mathrm{~W} / \mathrm{m}^{2}$ (24th August) to $20 \mathrm{~W} / \mathrm{m}^{2}$ (16th July). Similarly, the net SW flux varied from $30 \mathrm{~W} / \mathrm{m}^{2}$ (24th August) to $214 \mathrm{~W} / \mathrm{m}^{2}$ (25th August). As the variation of the reflected radiation is very little, the variation of the net SW flux is similar to that of the incoming SW flux. An inverse relation between incoming shortwave radiation and cloud amount is noticed during phase IV only. SST variations are controlled by net shortwave radiation absorbed in the ocean.

\subsubsection{Longwave (LW) fluxes}

The daily variation of the LW flux is very little (figure 6). The incoming LW flux varies from $394 \mathrm{~W} / \mathrm{m}^{2}$ (17th July) to $447 \mathrm{~W} / \mathrm{m}^{2}$ (15th August). The outgoing LW flux varies from $443 \mathrm{~W} / \mathrm{m}^{2}$ (24th August) to $474 \mathrm{~W} / \mathrm{m}^{2}$ (28th July). The outgoing LW flux is slightly greater than the incoming. On some days, both the LW fluxes are almost equal. Therefore, the net LW flux varies from $0.46 \mathrm{~W} / \mathrm{m}^{2}$ (24th August) to $68 \mathrm{~W} / \mathrm{m}^{2}$ (16th July).

\subsection{Variability of surface meteorological parameters}

The surface meteorological observations taken at 3 hours interval onboard SD contains SST, air temperature, wet-bulb temperature, atmospheric pressure, wind, cloud amount and types. The range of these parameters are presented.

\subsection{Mean daily variation of the radiative fluxes vs surface meteorological parameters}

The incoming longwave radiation is controlled by vapour pressure of air $(32-36 \mathrm{hPa})$ and air temperature $\left(25.6-29.6^{\circ} \mathrm{C}\right)$. The outgoing longwave radiation is controlled by SST variations. The cloud amount varied between 4 and 8 oktas. During phase I and III the cloud amount and SST are showing the same trend. Wind speed influence is also noticed on SST and air temperature. The difference in SST and air temperature
(SST-air temp) variation is positive during phase I and in the remaining phases small negative values are noticed.

\section{Summary and conclusions}

The variations of the four radiative fluxes and surface meteorological parameters over the south Bay of Bengal during the BOBMEX field experiment (July-August 1999) are examined on hourly and daily basis.

The mean albedo over the south Bay of Bengal varied from a minimum of 0.05 (clear sky) to 0.13 (overcast sky) and there is a clear inverse relationship between albedo and $\sin h$.

Incoming shortwave radiation, short term fluctuations are due to cloud type rather than cloud amount. In the presence of low clouds $(\mathrm{Cu}$ and $\mathrm{Cb}$ ) during noon time, reduced values are noticed. During 10:00-14:00 hrs the range of SW (incoming) values are $391 \mathrm{~W} / \mathrm{m}^{2}$ (phase II) $898 \mathrm{~W} / \mathrm{m}^{2}$ (11 hrs, phase I). The reflectivity of the shortwave radiation is fairly constant $\left(3 \mathrm{~W} / \mathrm{m}^{2}-20 \mathrm{~W} / \mathrm{m}^{2}\right)$. The incoming longwave radiation is high $\left(390 \mathrm{~W} / \mathrm{m}^{2}-457 \mathrm{~W} / \mathrm{m}^{2}\right)$ due to high vapour pressure of air $(>31.5 \mathrm{hPa})$ and changes in air temperature $\left(25.6^{\circ} \mathrm{C}-29.7^{\circ} \mathrm{C}\right)$. The outgoing longwave radiation is also large $\left(445 \mathrm{~W} / \mathrm{m}^{2}-469 \mathrm{~W} / \mathrm{m}^{2}\right)$ due to high SST $\left(>28.2^{\circ} \mathrm{C}\right)$ during this period. However, the changes in the net longwave radiation are small $\left(68 \mathrm{~W} / \mathrm{m}^{2}-0.46 \mathrm{~W} / \mathrm{m}^{2}\right)$ due to radiative saturation of the atmosphere near the ocean surface. The variation of net radiation is almost equal to the net shortwave flux, as the changes in the net longwave radiation are small. During phase IV low pressure period, the incoming shortwave radiation is drastically reduced and controlled by cloud amount and type followed by reduction in SST, atmosphere pressure and outgoing longwave radiation as shown in figures $2(\mathrm{~d})$ and 6 . The longwave flux and the net radiative flux have significant negative impact on the daily SST on the subsequent two days.

There is a significant difference between the outgoing shortwave flux and SST during the active and 
weak phases of monsoon over India. An SST warming of $29^{\circ} \mathrm{C}$ (higher SST reported) on 10th August produces the cloud (8 oktas), which in turn reduced the incoming shortwave radiation to $214 \mathrm{~W} / \mathrm{m}^{2}$ and thus maintains small SST variations.

\section{Acknowledgements}

The authors express their thankfulness to the Department of Science and Technology (DST), New Delhi for supporting this study by providing funds. The authors sincerely thank the National Physical Oceanographic Laboratory (NPOL), Cochin for providing facilities to collect the data onboard INS Sagardhwani and also thank the crew of the vessel for their constant help during the cruises. The authors express their special thanks to the India Meteorological Department (IMD) for providing the data and supporting BOBMEX. The authors also thank the Indian Institute of Science, Bangalore for providing constant help in collecting quality radiation data.

We are grateful to the referee for comments and suggestions on the earlier version of the manuscript which led to substantial improvement in the final manuscript.

\section{References}

Anderson E R 1952 Energy budget studies; U.S. Geol. Surv. Circ. 229 71-119

Bhat G S et al 2000 BOBMEX Inter-comparison Report, ICRP-1 $19 \mathrm{pp}$.

Bhat G S, Harish Kumar P V, Kalsi S R, Madhusoodanan P, Murty V S N, Prasad Rao C V K, Ramesh Babu V, Rao L V G, Ravichandran M, Reddy K G, Sanjeeva Rao P, Sengupta D, Sikka D R, Swain J and Vinayachandran P N 2001 BOBMEX-The Bay of Bengal Monsoon Experiment; Bull. Am. Meteorol. Soc. 82 2217-2243

Fung Y I, Harrison D E, Lacis A A 1984 On the variability of the net longwave radiation at the ocean surface; Reviews of Geophysics and Space Physics 22 177-193

Katsaros K B and DeVault J E 1986 On irradiance measurement errors at sea due to tilt of radiometers; J. Atmos. Oceanic Tech. 3 740-745

MacWhorter M A and Weller R A 1991 Error in measurements of incoming shortwave radiation made from ships and buoys; J. Atmos. Oceanic Tech. 8 108-117

Gopala Reddy K and Fechner H 1987 On the energy balance at the sea surface of Kiel Bay in summer 1983 and 1984; Meteorol. Rdsh. 40 pp. 53-62

Lumb F E 1964 The influence of cloud on hourly amounts of total solar radiation at the sea surface; Q.J.R.M.S. 90 $43-56$

Payne R E 1972 Albedo of the sea surface; J. Atmos. Sci. 29 959-970

Seller W D 1965 Physical climatology (Chicago \& London: The University of Chicago Press) $272 \mathrm{pp}$.

Sikka D R and Gadgil S 1980 On the maximum cloud zone and the ITCZ over India longitude during the southwest monsoon; Mon. Weather Rev. 108 179-195 